\title{
Validity of capital asset pricing model in Pakistan: Evidence from Karachi Stock Exchange
}

\author{
Syed Ali Raza ${ }^{1 \star}$ Syed Tehseen Jawaid ${ }^{1}$, Imtiaz Arif ${ }^{1}$ and Fahim Qazi ${ }^{2}$ \\ ${ }^{1}$ IQRA University, Karachi-75300, Pakistan. \\ ${ }^{2}$ Dadabhoy Institute of Higher Education, Karachi, Pakistan.
}

Accepted 26 October, 2011

\begin{abstract}
This study investigates the validity of capital asset pricing (CAP) model in Karachi Stock Exchange (KSE). The data used in this study were collected from 387 companies of 30 different sectors on monthly, quarterly and semi-annual basis. The Paired sample t- test is applied to find the difference between actual and expected returns. Results show that capital asset pricing model (CAPM) predict more accurately the expected return on a short term investment as compare to long term investment. It is recommended that the investors should more focus on CAPM results for short term as compare to long term investments in KSE.
\end{abstract}

Key words: Portfolio choice, investment decisions, capital assets pricing model, risk.

\section{INTRODUCTION}

Capital asset pricing model (CAPM) is one of the central model use by portfolio managers, professional and investors to predict the expected risk and expected return on investment. The main focal point of CAP model is to check whether the returns are statistically related to risks (betas). According to CAP model the investor needs to be compensated in two ways, for time value of money (risk free rate) and for taking risk. The CAP model was introduced by Jack Treynor, John Lintner, William Sharpe and Jan Mossin in the early 1960's and was further refined later (Bodie et al., 2003).

The findings and results of CAP model are very mix. The results of studies from late sixties, seventies and early eighties supported the validity of CAP Model (Black et al., 1972; Fama and MacBeth, 1973; Blume and Friend, 1973; Lau and Quay, 1974; Dowen, 1988; Jagannathan and Wang, 1993; Jagannathan and McGrattan, 1995). In these decades, it is concluded that the CAP model is able to predict the expected return on investments. But in the mid of eighties, it was found that

*Corresponding author. E-mail: syed_aliraza@hotmail.com. Tel: 92-333-3448467. the single risk factor model does not accurately predict the expected return on stocks because there are so many other factors affecting the returns on investments such as firm size, market value, financial ratios, price earnings ratio, economic conditions, seasonality effect, inflation (Banz, 1981; Basu, 1983; Tinc, 1984; Groenewold and Fraser, 1997; Scheicher, 2000).

Karachi Stock Exchange (KSE) is not a sustainable market and investors find fluctuations in prices of stocks, for that reason, Karachi stock exchange have very different risk-return relationship. The investors discover that the market goes up or down dramatically in a few sessions. In December 2008, in the Karachi stock exchange, 100 index was down to 3300 points from 9187 points to 5865 points in just 13 trading sessions. After two months, the 100 index of Karachi stock exchange was up to 2638 points from 5707 points to 8345 points in just 19 trading sessions. ${ }^{1}$

The main problem of KSE for investors and portfolio managers is to quantify the risk associated with securities and expected return on bearing this risk. Therefore, the main objective of this study is to determine how accurately the capital asset pricing model predicts the

\footnotetext{
${ }^{1}$ Information is gather from official website of KSE: www.kse.com.pk
} 
expected return and risk associated with securities listed on Karachi stock exchange.

\section{LITERATURE REVIEW}

In respect to the literatures regarding to the empirical test of the CAPM, many researchers have already engaged in relevant studies in financial markets of different countries.

\section{Theoretical background}

The risk is divided into two parts; unsystematic and systematic risk. The unsystematic risk is related to specific company, industry or security, it is also known as diversifiable or specific risk. The unsystematic risk can be eliminated by diversification. The systematic risk is related to entire market or entire financial system, it also known as un-diversifiable or market risk (Interest rate, Recession, wars). The systematic risk is directly affecting the entire market and it cannot be eliminated by diversification (Bodie et al., 2003). Diversification can be defined by a proverb "do not put your all eggs in one basket". In diversification the investors reduced the risk by investing in a variety of securities.

In capital assets pricing model the (CAPM), unsystematic risk is eliminated through efficient diversification. The capital assets pricing model (CAPM) is mainly discussing about the systematic risk; the risk related to entire market. The measure of a systematic risk in CAPM is the beta. The capital assets pricing models argues that, the expected return on investment or on security will be positively related to its market beta, that's mean higher or lower the security's beta the higher or lower the expected return on investment.

The basic belief of capital assets pricing model is that the investor needs to be compensated more than the risk free return. According to CAP model, the investor needs to be compensated in two ways, for time value of money (risk free rate) and for taking risk (beta of security). The capital assets pricing model was developed in hypothetical world with certain assumptions (Bodie et al., 2003; Horne, 2006; Copeland, 2007). (i) There are many investors in market. (ii) All investments are for the same period of time. (iii) There are no taxes on trading. (iv) There is no transaction cost on trading. (v) All investors can lend and borrow unlimited amounts at the risk free rate. (vi) The investors are rational and risk averse. (vii) Investors have all and equal information. (viii) The investors have same expectations about expected returns. (ix) The investors deal with securities that are all highly divisible into small parts.

\section{Empirical studies}

Black et al. (1972) analyzed the impact of CAP model on New York stock exchange covering the period of 41 years from 1926 to 1966 . They found that CAPM is applicable on New York stock exchange and they found positive relationship between beta and average return, that is, the investor will get high return on high risk securities. They also concluded that the CAPM model accurately predicts the expected return on securities.

Lau and Quay (1974) analyzed the validity of CAP model on Tokyo stock exchange. They used the data of period of 100 companies listed on Tokyo stock exchange for the period of five years (1964-1969). They found that the CAP model accurately predicts the expected return of stocks and they concluded that CAP model is perfectly applicable on Tokyo stock exchange.

Dowen (1988) argued in the favor of CAPM, he concluded that investors may use beta as a tool but not as their only tool. He also concluded that, there is no sufficiently large portfolio guarantee the elimination of non systematic risk. Cheung and Wong (1992) analyzed the Hong Kong equity market from the period of 1980 to 1989 to study the relationship between risk and return in Hong Kong equity market. They concluded that applicability and validity of CAP model is very weak in Hong Kong stock market. Cheung et al. (1993) analyzed the Korean and Taiwan stock exchanges to study the relationship between risk and return in emerging Asian markets. They concluded that the applicability and validity of CAP model is very weak in both markets, especially in Taiwan stock exchange.

Jagannathan and Wang (1993) argued that the capital assets pricing model (CAPM) is a widely used model to predict the risk of investment and expected return of the stocks among the investors and portfolio managers. Groenewold and Fraser (1997) used data of eight sectors of Australian stock exchange for the period from 1983 to 1993 to make comparison between CAP model, GARCH model and arbitrage pricing theory (APT) model. They found that the GARCH model and APT model provides almost the same results and both models accurately predict the expected return of securities. They also concluded that, the results of CAP model do not match with actual situations and provide misleading results to investors.

Huang (2000) analyzed the validity of CAP model on two different sets of securities. He used the data of 93 companies from the period of 1986-1993. He used two different sets of securities in first set, he selected high risk securities and in second set, he selected low risk securities. He found in their research that, CAPM is accurately predicting the expected returns of low risk securities and give consistent results. On the other side, the high risk securities gave inconsistent results with CAPM, this means that CAPM is not accurately predicting the expected return of high risk securities. He concluded that on the high risk securities, the CAPM does not validate their results and CAPM does not accurately predicts the expected return on investments and investors could not relied upon CAP model.

Scheicher (2000) researched on 12 companies listed 
on German stock exchange for the period of 23 years. He found that the expected return was not just predicted by a single risk factor. There are some other factors also affecting the returns of investments. He concluded that the results of other models like multi risk factor model and GARCH model more accurately predicts the expected return of investments on stock than CAPM model. Gomez and Zapatro (2003) analyzed the data of 220 US securities covering period of twenty six year from 1973 to 1978. They used two betas model considering the systematic market risk factor and active management risk factor. They concluded that the result of their two betas model is better than CAPM.

Fraser and Hamelink (2004) made comparison between the results of CAP model and GARCH model. They researched on seven sectors of London stock exchange covers period of twenty two years (1975-1976). They found that the results of $\mathrm{GARCH}$ model more accurately predicts the expect return in compare to CAP model. Quo and Perron (2005) analyzed the data of 50 companies listed on New York stock exchange from the period of 1978 to 2004 . They concluded that the capital asset pricing model only identify single risk factor and investor get wrong estimation of the expected return on their investments.

Grigoris and Stavros (2006) found that the basic statement or assumption of high return on high risk does not fulfill on Greek stock market. They used data of 100 companies of Athens stock exchange covering the period of five years from 1998 to 2002 . They also concluded that the results of CAPM are consistent for shorter period but overall the CAPM does not provide accurate and consistent results. Hui and Christoper (2008) used the data of 95 companies of United States and Japan stock markets for the period of 11 years from 1996 to 2006 . They found that CAP model does not provide accurate and consistent results when applied to stock markets of Japan and United States.

Eatzaz and Attiya (2008) made comparison between the CAP model and conditional multi risk factor model. They used data of 49 companies of Karachi stock exchange from the period of 1993 to 2004. They concluded that the results of CAPM model are consistent and accurate with only few securities and only for few years. They also found that multi risk factor model predicts more accurately results as compare to CAP model. Raei and Mohammadi (2008) analyzed the data of 70 companies listed on NASDAQ stock market for the period of twelve years from 1994 to 2005. They concluded that methods of estimating expected return have been changed; CAPM is just useful for calculating cost of capital. They also found that the returns from CAPM models are always lower than compare to multi factor model (APT). They suggested that APT provide more accurate result compare to CAPM.

Tony Head (2008) argued that although the CAPM is widely used for predicting the expected return on stocks but the results of previous research have not always positively supported this model. Like many other models the main reason of criticism is a certain assumptions of CAP model. Hanif (2010) analyzed the validity of CAP model on Tobacco sector of Karachi stock exchange covering the period from 2004 to 2007 . He found that CAP model is not applicable on Tobacco sector of Karachi stock exchange and the results of CAP model do not match with actual results.

Hanif and Bhatti (2010) analyzed the validity of CAP model on 60 firms listed on Karachi stock exchange covering the period from 2003 to 2008 . They found that CAP model is not applicable on of Karachi stock exchange and the results of CAP model do not match with actual results. They concluded that the results of only 28 observations out of 360 observations are supporting CAPM.

\section{METHODOLOGY}

The monthly, quarterly and semiannually actual returns of stock and return of market are calculated by following formula:

$\mathrm{R}=(\mathrm{CP}-\mathrm{OP}) / \mathrm{OP}$

Whereas, $\mathrm{R}$ is the actual return, $\mathrm{CP}$ and $\mathrm{OP}$ are the closing and opening value of stock prices and market index. We calculate Beta of each sector by regression analysis. We calculate expected return of each sector by CAPM equation:

$R A=R F+B(R M-R F)$

Whereas, $R A$ is the expected return on sector $A, R F$ is the risk free rate; $B$ is the systematic risk; the risk related to entire market, $R M$ is the average market return. We use statistical tool "Paired Sample ttest" to analyze the significance of difference between actual returns and expected returns.

To find the validity of CAPM we use secondary type of data. All the secondary data is gathered from following sources: website of Karachi stock exchange ${ }^{2}$, record room of Brokerage house, website of state bank of Pakistan. ${ }^{3}$ We used the data of stock prices and index value, the rate of treasury bills issued by government is used in this analysis as a risk free rate (Ataullah, 2001; Sipra, 2006; Hanif and Bhatti, 2010). This research is conducted on 387 companies listed on 30 sectors of Karachi stock exchange to test the applicability and validity of Capital Asset Pricing Model.

The results of studies from late sixties, seventies and early eighties supported the validity of CAPM Model. But in the mid of eighties it is found that the single risk factor model does not accurately predict the expected return on stocks because there are so many other factors affecting the returns on investments. In past studies the researchers did not use any statistical tool for determine the difference between actual and expected return is significant or not. In this research we use statistical tool "Paired Sample t- test" to analyze the significance of difference between actual and expected return.

\section{ESTIMATION AND RESULTS}

From the monthly, quarterly and semi annually data the

\footnotetext{
${ }^{2}$ The web link is: www.kse.com.pk

${ }^{3}$ The web link is www.sbp.org.pk
} 
Table 1. Results on monthly basis.

\begin{tabular}{|c|c|c|c|c|}
\hline S/No. & Sectors & Beta & t-statistics & Prob. \\
\hline 1 & Automobile and parts & 0.155 & -0.488 & 0.643 \\
\hline 2 & Banks & 0.466 & -0.294 & 0.779 \\
\hline 3 & Beverages & 0.115 & -0.172 & 0.869 \\
\hline 4 & Bonds & 0.289 & -0.642 & 0.545 \\
\hline 5 & Chemical & 0.277 & -1.141 & 0.297 \\
\hline 6 & Construction and material & 0.235 & -2.262 & 0.064 \\
\hline 7 & Electricity & 0.236 & -1.418 & 0.206 \\
\hline 8 & Electronic and electrical equipment & 0.299 & -0.663 & 0.532 \\
\hline 9 & Equity investment instruments & 0.233 & -2.528 & 0.045 \\
\hline 10 & Financial services & 0.270 & -1.195 & 0.277 \\
\hline 11 & Fixed line telecommunication & 0.308 & -0.993 & 0.359 \\
\hline 12 & Food producers & 0.089 & 0.804 & 0.452 \\
\hline 13 & Forestry and paper & 0.239 & -2.632 & 0.039 \\
\hline 14 & Gas water and multi utilities & 0.176 & -1.202 & 0.275 \\
\hline 15 & General industries & 0.266 & -0.608 & 0.565 \\
\hline 16 & Health care equipment and services & 0.204 & 1.050 & 0.334 \\
\hline 17 & Household goods & 0.139 & -2.991 & 0.024 \\
\hline 18 & Industrial engineering & 0.208 & -0.173 & 0.869 \\
\hline 19 & Industrial metals and mining & 0.301 & -1.459 & 0.195 \\
\hline 20 & Industrial transportation & 0.275 & -0.477 & 0.65 \\
\hline 21 & Leisure goods & 0.204 & -0.932 & 0.387 \\
\hline 22 & Life insurance & -0.015 & -0.680 & 0.522 \\
\hline 23 & Non life insurance & 0.387 & -0.840 & 0.433 \\
\hline 24 & Oil and gas & 0.362 & -0.540 & 0.609 \\
\hline 25 & Personal goods & 0.270 & -1.633 & 0.154 \\
\hline 26 & Pharma and bio tech & 0.154 & -1.943 & 0.1 \\
\hline 27 & Support services & 0.345 & -0.489 & 0.642 \\
\hline 28 & Technology hardware and equipment & 0.887 & -0.178 & 0.865 \\
\hline 29 & Tobacco & 0.220 & 0.261 & 0.803 \\
\hline 30 & Travel and leisure & 0.170 & -0.005 & 0.996 \\
\hline
\end{tabular}

actual and CAPM return are calculated by formulas and statistical tools for the analysis and findings of this study. According to the past studies the capital asset pricing model gives mixed results when applied on the stock markets of different countries. The CAPM provide accurate results or return on a certain securities for some years on the other side it does not give accurate results in some years. We also find some mixed but mostly favorable results when applied the CAPM on Karachi stock exchange and make comparison between different sectors.

The beta coefficient is states the relation between movement in particular security and movement in the market. Normally the value of beta of larger blue chip stocks are between zero and one but many stocks have higher beta value because they are much more responsive to market. If the value of beta is zero that's mean the return on particular security is independent of the market (Risk free securities, treasury bills or bonds issued by government). If the value of beta is 0.5 that is mean the stock is only half as sensitive as the market, beta less than 0.5 are also known as defensive beta. If the value of the beta is 1 that's mean the particular security and market both have the same sensitivity. The value of beta between 1 and 0.5 are also known as normal beta. If the value of the beta is 2 that's mean the particular stock is double as sensitive or riskier as the market.

\section{Monthly basis}

Results on monthly basis is shown in Table 1. The value of beta is gotten from Table 1 . When we run the regression analysis on data from 2004 to 2011 on a monthly basis, we find that there is no sector have aggressive beta. There is only one sector having normal beta; technology hardware and equipment. There are total 29 sectors out of 30 sectors having defensive beta, some of these sectors are very close to risk free sector or 
Table 2. Results on quarterly basis.

\begin{tabular}{|c|c|c|c|c|}
\hline S/No. & Sectors & Beta & t-statistics & Prob. \\
\hline 1 & Automobile and parts & 0.484 & -1.334 & 0.231 \\
\hline 2 & Banks & 1.046 & -1.939 & 0.101 \\
\hline 3 & Beverages & 0.107 & -0.294 & 0.778 \\
\hline 4 & Bonds & 0.814 & -1.986 & 0.094 \\
\hline 5 & Chemical & 0.432 & -1.419 & 0.206 \\
\hline 6 & Construction and material & 0.510 & -3.442 & 0.014 \\
\hline 7 & Electricity & 0.479 & -3.049 & 0.023 \\
\hline 8 & Electronic and electrical equipment & 0.270 & -0.321 & 0.759 \\
\hline 9 & Equity investment instruments & 0.437 & -2.534 & 0.044 \\
\hline 10 & Financial services & 0.866 & -2.096 & 0.081 \\
\hline 11 & Fixed line telecommunication & 0.783 & -1.047 & 0.335 \\
\hline 12 & Food producers & 0.293 & 0.144 & 0.890 \\
\hline 13 & Forestry and paper & 0.264 & -3.054 & 0.022 \\
\hline 14 & Gas water and multi utilities & 0.714 & -0.716 & 0.501 \\
\hline 15 & General industries & 0.529 & -1.274 & 0.250 \\
\hline 16 & Health care equipment and services & 0.633 & -0.056 & 0.957 \\
\hline 17 & Household goods & 0.364 & -3.919 & 0.008 \\
\hline 18 & Industrial engineering & 0.441 & -1.104 & 0.312 \\
\hline 19 & Industrial metals and mining & 0.646 & -2.683 & 0.036 \\
\hline 20 & Industrial transportation & 0.490 & -1.536 & 0.176 \\
\hline 21 & Leisure goods & 0.345 & -2.134 & 0.077 \\
\hline 22 & Life insurance & 0.061 & -0.718 & 0.500 \\
\hline 23 & Non life insurance & 0.507 & -1.097 & 0.315 \\
\hline 24 & Oil and gas & 0.733 & -1.260 & 0.254 \\
\hline 25 & Personal goods & 0.439 & -3.740 & 0.010 \\
\hline 26 & Pharma and bio tech & 0.261 & -2.350 & 0.057 \\
\hline 27 & Support services & 0.940 & -1.365 & 0.221 \\
\hline 28 & Technology hardware and equipment & 0.516 & 0.128 & 0.902 \\
\hline 29 & Tobacco & 0.411 & -0.258 & 0.805 \\
\hline 30 & Travel and leisure & 0.009 & -0.064 & 0.951 \\
\hline
\end{tabular}

very defensive sectors; automobile and parts, beverages, food producers, gas water and multi-utilities, household goods, life insurance, travel and leisure.

Paired sample t- test was applied to find the p-value which indicates the significance of difference between actual and expected return. If the $p$-value is less than 0.05 , there is a significant difference between actual return and CAPM return. When we analyze the data on monthly basis, we found the significant difference in only 3 sectors out of 30 sectors; equity Investment instruments, forestry and papers, household goods. The results of twenty seven sectors out of 30 sectors show that there is no significance difference in between actual return and CAPM returns. This confirms the validity of capital asset pricing model on Karachi stock exchange. The CAPM accurately predicts the expected return of different sectors of Karachi stock exchange.

Our results was not in consistent with the findings of Hanif and Bhatti (2010), where they found that CAPM is not providing accurate result in most of time when applied on Karachi stock exchange. Our findings are partially consistent with the findings of Eatzaz and Attiya, (2008) where they found that the CAPM is not fully applicable in Pakistani Stock Market. Our findings are consistent with the results of Lau and Quay (1974), they found that CAPM provides the accurate results when applied on Tokyo Stock Exchange.

\section{Quarterly basis}

Results on quarterly basis is shown in Table 2. From Table 2, we got the value of beta. When we run the regression analysis on data from 2004 to 2011 on a quarterly basis, we found that only one sector have aggressive beta; banks. There are 13 sectors out of 30 sectors having normal beta, some of them are very close to beta equal to one and having high normal beta; bonds, financial services, fixed line telecommunication, support services. There a re total of 16 sectors having 
Table 3. Results on semiannually basis.

\begin{tabular}{clccc}
\hline S/No. & Sectors & Beta & t-statistics & Prob. \\
\hline 1 & Automobile and parts & 0.619 & -0.759 & 0.482 \\
2 & Banks & 1.083 & -1.119 & 0.314 \\
3 & Beverages & 0.188 & 0.078 & 0.940 \\
4 & Bonds & 0.751 & -3.691 & 0.014 \\
5 & Chemical & 0.584 & -1.732 & 0.144 \\
6 & Construction and material & 0.647 & -6.731 & 0.001 \\
7 & Electricity & 0.493 & -3.970 & 0.011 \\
8 & Electronic and electrical equipment & 0.263 & -1.253 & 0.266 \\
9 & Equity investment instruments & 0.358 & -4.232 & 0.008 \\
10 & Financial services & 0.776 & -1.378 & 0.227 \\
11 & Fixed line telecommunication & 0.810 & -0.341 & 0.747 \\
12 & Food producers & 0.368 & -0.215 & 0.838 \\
13 & Forestry and paper & 0.378 & -3.507 & 0.017 \\
14 & Gas water and multi utilities & 0.536 & -0.721 & 0.503 \\
15 & General industries & 0.637 & -1.394 & 0.222 \\
16 & Health care equipment and services & 0.630 & -0.680 & 0.527 \\
17 & Household goods & 0.419 & -3.562 & 0.016 \\
18 & Industrial engineering & 0.692 & -0.873 & 0.423 \\
19 & Industrial metals and mining & 0.703 & -3.602 & 0.016 \\
20 & Industrial transportation & 0.512 & -0.798 & 0.461 \\
21 & Leisure goods & 0.224 & -2.394 & 0.062 \\
22 & Life insurance & 0.017 & 0.299 & 0.777 \\
23 & Non life insurance & 0.804 & -0.714 & 0.507 \\
24 & Oil and gas & 0.802 & -1.124 & 0.312 \\
25 & Personal goods & 0.453 & -4.438 & 0.007 \\
26 & Pharma and bio tech & 0.383 & -1.577 & 0.176 \\
27 & Support services & 0.916 & -0.647 & 0.546 \\
28 & Technology hardware and equipment & 1.317 & 0.220 & 0.834 \\
29 & Tobacco & 0.575 & -1.766 & 0.138 \\
30 & Travel and leisure & -0.004 & 0.175 & 0.868 \\
\hline & & & &
\end{tabular}

defensive beta, some of these sectors are very close to risk free sector or very defensive sectors; beverages, life insurance, travel and leisure.

We found the significant difference in only 7 sectors out of 30 sectors; construction and material, electricity, equity Investment instruments, forestry and papers, household goods, Industrial metal and mining, Personal goods. The results of twenty three sectors out of 30 sectors showed that there is no significance difference in between actual return and CAPM returns. This confirms the applicability of capital asset pricing model on Karachi stock exchange.

\section{Semiannually basis}

Results on semiannually basis is shown in Table 3. From Table 3, we got the value of beta. When we run the regression analysis on data from 2004 to 2011 on a semiannual basis, we found that only two sectors have aggressive beta; banks and technology hardware and equipment. There are 16 sectors out of 30 sectors having normal beta, some of them are very close to beta equal to one and having high normal beta; fixed line telecommunication, non life insurance, oil and gas, support services. There are total 12 sectors having defensive beta, some of these sectors are very close to risk free sector or very defensive sectors; beverages, life insurance, travel and leisure.

The calculation of Beta on a monthly and quarterly basis shows decrease in beta as compared to semi annually basis. The sectors are shifted from aggressive to normal position and normal to defensive position. In semi annually basis, we have two sectors having aggressive beta but in monthly basis, we have no sector having aggressive beta. Likewise, in semi annually basis, we have 16 sectors having normal beta but in monthly basis, we have only one sector who has normal beta. It means sectors are moving with market on semi annually basis. Our results of this movement of beta are consistent with the findings of Hanif (2010), where he found that 
securities are not moving with market on a short term basis, they are moving on long term basis.

Our results of beta could not consistent with the findings of Huang (2000) where he found that CAPM is only applicable in low risk securities or with defensive securities. Our results shows different picture, the bank sector have beta (1.08) and it has p-value (0.314) that's means it has high aggressive beta but there is no significant difference in actual return and CAPM return in Banking sector of Karachi stock exchange.

We found the significant difference in only 8 sectors out of 30 sectors; bonds, construction and material, electricity, equity Investment instruments, forestry and papers, household goods, Industrial metal and mining, Personal goods. The results of twenty two sectors out of 30 sectors showed that there is no significance difference between actual return and CAPM returns. This confirms the applicability of capital asset pricing model on Karachi stock exchange.

It was also found that CAPM, more accurately predicts the expected return on a short term investment, in monthly basis, we find there is no significant difference in return of 27 sectors as compared to 22 sectors in semiannual basis. Our findings are partially consistent with Grigoris and Stavros, (2006) they found that the results of CAPM are consistent for shorter period but overall the CAPM does not provide accurate and consistent results.

\section{CONCLUSION AND MANAGERIAL IMPLICATIONS}

In recent literature, the validity and implications of CAP model has been widely discussed. After reviewing the academic literature and empirical studies, the relationship between the actual returns and CAPM returns are found very mix. The results of studies from late sixties, seventies and early eighties supported the validity of CAP Model. But in the mid of eighties, it is found that the single risk factor model does not accurately predict the expected return on stocks because there are so many other factors affecting the returns on investments. The paired sample t- test concluded that CAPM accurately predicts the expected return of different sectors of Karachi stock exchange. Findings indicate that CAPM predicts more accurately the expected return on a short term investment, in monthly basis, there is no significant difference in return of 27 sectors as compared to 22 sectors in semiannual basis. Results show that the beta on a quarterly and monthly basis showed decrease in beta as compared to semi annually basis. It means sectors are moving with market on semi annually basis.

It is recommended that the investors should be more focus on CAPM results for short term investments (monthly) as compare to long term investments (quarterly and semiannually) in KSE. The investors can get better predicted returns by CAP model on investments of monthly basis as compare to quarterly basis, and quarterly basis as compare to semiannual basis. The shorter the period the returns will be more accurately predicted by CAPM. The investors of KSE also quantify their expected risk on their investments by CAPM. The future area of research may include the comparing of statistically analyzed CAPM return with multifactor models like APT and GARCH model.

\section{REFERENCES}

Ataullah A (2001). Macroeconomic Variables as Common Pervasive Risk Factors and Empirical Content of the Arbitrage Pricing Theory in Pakistan. Lhr. J. Econ., 6 (1 ): 55-74.

Banz RW (1981). The Relationship between Return and Market Value of Common Stock. J. Finan. Econ., 3-18.

Basu S (1983). The Relationship between Earnings' yield, Market Value and Return for NYSE Common Stock: Furthur evidence. J. Finan. Econ., pp. 129-156.

Black F, Jense M, Scholes M (1972). The Capital Assets Pricing Model: Some Empirical Results. Studies in the theory of capital market, Prager Publishers

Blume M E, Friend I (1973). A new look at the Capital Asset Pricing Model. J. Finan., 28(1): 19-33.

Bodie I, Kane A, Marcus AJ (2003). Essentials of Investments. (fifth, Ed.) Mcgraw-Hill.

Cheung YL, Wong KT (1992). An assesment of Risk and Return: some empirical findings from Hong Kong Stock Exchange. Appl.Fina. Econ., 2: 105-114.

Cheung YL, Wong KA, Ho YK (1993). The pricing of risky assets in two emerging asian markets: Korea and Taiwan. Appl. Finan. Econ., 3: 315-324.

Copeland WS (2007). Financial Theory and Corporate Policy 4th Edition. Pearson Education FOundation, Delhi, India.

Dowen RJ (1988). Beta, Non-systematic risk and Portfolio Selection. Appl. Econ., 20: 221-228.

Eatzaz A, Attiya YJ (2008). Testing Multi Factor Capital Asset Pricing Model in Case of Pakistani Market. Int. Res. J. Finan. Econ., 25:, 114-138.

Fama EF, MacBeth JD (1973). Risk, Return and Equillibrium: Empirical Test. J. Polit. Econ., 81: 607-636.

Fraser P, Hamelink F (2004). Time-varying Betas and the Cross Sectional return risk relation: Evidence from the UK. Euor. J. Finan. 10(4): 255-276.

Gomez JP, Zapatro F (2003). Asset Pricing implications of benchmarking: a two-factor CAPM. Euro. J. Finan., 9(4): 343-357.

Groenewold N, Fraser P (1997). Share Prices and Macroeconomics Factor. J. Bus. Financ. Acoount., 24: 1367-1383.

Grigoris M, Stavros T (2006). Testing the CAPM: The case of the emerging Greek Securities Market. Int. J. Finan, Econ.,pp: 78-91.

Hanif M (2010). Testing Application of CAP Model on KSE- Pakistan: A Case Study on Tobacco Sector. Manag. Account., 2(1):192-215.

Hanif M, Bhatti U (2010). Validity of Capital Assets Pricing Model: Evidence from KSE-Pakistan. Euro. J.Econ. Finan. Adm. Sci., Issue 20:148-161.

Head T (2008). CAPM: Theory, Advantages and Dis advantages. J.Finan., 27( 5) : 175-197.

Horne V (2006). Fundamentals of Financial Managemnt, 12th Eition. Prencitic Hall Publisher Ltd.

Huang HC (2000). Test of regimes - Switiching CAPM. J. Finan., 10 : 573-578.

Hui G, Christopher JN (2008). Return Volatility in Priced in Equities. Fin. Manage. Assos. Int., 37( 4): 769-790.

Jagannathan R, McGrattan E R (Fall 1995). The CAPM Debate. Federal Reserve Bank of Minneapolis Quart. Rev., 19(4): 2-17.

Jaggannath R, Wang Z (1993). CAPM is alive as well. Fourh Annu. Conf. Finan. Econ. Account., 1(5): 2-57.

Lau SC, Quay SR, Ramsey CM (1974). The Tokyo Stock Exchange and Capital Assets Pricing Model. J.Finan., 29(2): 507-514. 
Quo Z, Perron P (2005). Estimamting and testing structural changes in multivariate regressions. J.Econom., 12 ( 8 ): 547-573.

Raei R, Mohammadi S (2008). Fractional return and fractional CAPM. Appl. Finan. Econ. Lett., 4: 269-275.

Scheicher M (2000). Time-varying risk in the German Stock Market. Euro. J. Finan., 6: 70-91.

Sipra N (2006). Mutual Fund Performance in Pakistan, 1995-2004. Cent. Manage. Econ. Res., Working Paper No. 06-45.
Tinc SM (1984). Risk and return: January vs. the rest of the year. J.Finan. Econ., pp: 561-574.

www.sbp.org.pk (2011. June.).

www.kse.com.pk (2011. June.). 